\title{
A Review of Research on Catastrophic Formation and Evolutionary Mechanism of Deep High Stress Rock Mass under Impact Loading
}

\author{
Xinfeng Wang1,2,3*, Wenbo Luo ${ }^{3,4}$, Yipeng Li ${ }^{1}$ \\ ${ }^{1}$ School of Environment and Resources, Xiangtan University, Xiangtan, China \\ ${ }^{2}$ Key Laboratory of Safety and High-Efficiency Coal Mining, Ministry of Education, Anhui University of Science and Technology, \\ Huainan, China \\ ${ }^{3}$ Hunan Key Laboratory for Geomechanics and Engineering Safety, Xiangtan University, Xiangtan, China \\ ${ }^{4}$ School of Civil Engineering and Mechanics, Xiangtan University, Xiangtan, China \\ Email: *wangxinfeng110@126.com
}

How to cite this paper: Wang, X.F., Luo, W.B. and Li, Y.P. (2018) A Review of Research on Catastrophic Formation and Evolutionary Mechanism of Deep High Stress Rock Mass under Impact Loading. Open Journal of Civil Engineering, 8, 447-459.

https://doi.org/10.4236/ojce.2018.84031

Received: October 5, 2018

Accepted: November 2, 2018

Published: November 5, 2018

Copyright $\odot 2018$ by authors and Scientific Research Publishing Inc. This work is licensed under the Creative Commons Attribution International License (CC BY 4.0).

http://creativecommons.org/licenses/by/4.0/

(C) (i) Open Access

\begin{abstract}
With the exploitation of resources expanded to deep, the geological environment which is "three tenors one disturbance" of rock mass in great depth has been more complex, resulting in some new engineering geological disasters, such as rock burst, pressure bumping, large deformation of surrounding rock, brittle-ductile transition of rock and zonal disintegration of rock mass, which occur frequently in deep underground engineering rock mass. The impact load caused by collision, explosion, extrusion and outburst is the root cause of the dynamic instability of the deep rock mass. What should be emphasized is that high in-situ stress and blasting excavation disturbance complicate disaster developing mechanism of deep underground engineering rock mass and sharply increase the difficulty of controlling disaster. This paper is aimed at the research status and development trend, of which dynamic characteristics of deep high stress rock mass and its damage and failure effect each other under impact, and conduct analysis, in the later stage where I would discuss how to carry out the response law of the deep high-stress rock mass under the impact load and the mechanism of catastrophe developing, which is of great significance to build a model of instability and fracture evolution about deep rock mass under shock disturbance and to maintain its safety and stability.
\end{abstract}

\section{Keywords}

Deep Rock Mass, Impulse Loading, Catastrophe Developing Mechanism, 
Damage and Failure Effect

\section{Introduction}

With the rapid development of industrialization, the national economic development has increased the dependence for resources and energy. Owing to exhaustion of shallow mineral resources, the exploitation continues to move deeper into the earth and people expect to explore the underground space resources. In terms of resource exploitation, as well as presently, the depth of coal mining has reached $1500 \mathrm{~m}$, geothermal mining more than $3000 \mathrm{~m}$, non-ferrous over $4350 \mathrm{~m}$, and as to oil and gas resources, it has reached to $7500 \mathrm{~m}$. In the future, deep mining will become the new normal [1]. Since the rock mass deep excavated is in the complex geological environment of high crustal stress, high earth temperature, high karst water pressure and strong mechanical excavation, blasting vibration, impact unloading and mining disturbance, which is under the threats of severe dynamic phenomena as a state of "three tenors one disturbance", and it make its mechanical response of deep rock mass obviously distinct from that of the shallow rock mass.

During the excavation of deep rock mass, the engineering disaster problems are emerging; there are some new engineering geological disasters, such as rock burst, impulse earth pressure, large deformation of surrounding rock, brittle transition of rock and zonal disintegration of rock mass in deep underground engineering rock. In the process of deep rock excavation, the excavation rock not only bears the high static load, but also bears the influence of dynamic loads such as blasting vibration, so the stress condition is different from the shallow rock mass. In addition to the shallow rock shallow overburden, the ignored self weight stress can be excavation; only simply consider the blasting vibration caused by dynamic load, can better solve the problems under the rock dynamics. For similar to the deep excavation, if we apply the shallow solution, the effect is not ideal; hence the mechanics of deep rock response characteristics and catastrophe evolution behavior are the most difficult and focus of the study for rock mechanics circle.

However, deep underground engineering excavation, such as mining, tunnel excavation, high-speed impact, piling and explosion protection, and civil air defense projects personal protection, are involved into the rock dynamic problems of dynamic mechanical properties and dynamic failure under impact loading [2]. Impact loads caused by which collision, explosion, extrusion and outburst, are the origins of inducing deep rock mass to touch off catastrophic instability and result in dynamic disaster. High ground stress and blasting excavation disturbance complicate the catastrophe developing mechanism of underground engineering rock mass in great depth, and enhance the difficulty of disaster control. The rock mass in the deep underground engineering will be destroyed and dis- 
turbed in a great extent if the blasting technique is inappropriate or the blasting vibration effect is too high, leading to dynamic instability, engendering large deformation, fracture, crush and overall instability, more severe, it will cause engineering disaster. Therefore, in order to effectively control the rock mass in deep underground engineering, it is essential to master the structural characteristics and mechanical properties of the deep high stress rock mass, systematically study the transport law, deformation mechanism and failure mode of deep surrounding rock under impact loads, found out the catastrophic incubation mechanism, stress evolution law and impact dynamic response of deep high stress energy storage rock mass under strong impact disturbance, establish the time-space evolution model of deformation, instability, fracture and catastrophe induced by deep high stress rock mass under impact loads. This is of great theoretical significance and engineering value to study and predict the catastrophic mechanism of deep high stress rock mass under impact disturbance.

\section{Research Status and Trend Analysis}

\subsection{Research Status and Trend Analysis about Dynamic Characteristics of Deep Rock Mass with High Stress}

In the study of related problems refer to the deep rock mechanics and deep rock mass excavation engineering, many experts and scholars abroad have defined the concept of "great depth". Generally considered, the excavation of deep rock mass is due to the deep burial of the working-face, which leads to the technical problems which rarely encountered in the excavation process of some shallow rock. In the field of mining, South Africa, Canada and other countries regarded the mine reach to the depth of $800-1000 \mathrm{~m}$ as deep mining; Poland and Britain however provided their definition of deep well mining whose depth up to $750 \mathrm{~m}$; other countries believe that the mine depth is more than $600 \mathrm{~m}$ for deep mining. Differences among conceptions of definition of "great depth" within different countries, but the common point is that the depth of a certain mining is regarded as the criterion for distinguishing the deep and shallow parts. Nevertheless, the boundary criterion has some limitations in engineering application. In this regard scholars like professor. He combined with the special geological and mechanical environment in deep engineering by means of intensive study on the nonlinear mechanical characteristics of deep engineering rock mass, put forward the concept of "great depth" [3] [4] [5], which refers to the depth of the nonlinear mechanical phenomena and the following depth interval appearing in the engineering excavation rock mass with the increase of the excavation depth, and point out the difference of loading characteristics of deep rock mass between the shallow parts [6].

The engineering geological environment of deep rock has strong influence on its mechanical properties. The deep rock mass is subjected to higher horizontal stress besides the vertical stress caused by its weight, where the vertical stress distribution is relatively simple while the horizontal has more complicated 
change. According to the worldwide statistical data of in-situ stress measurement, the vertical stress increases linearly with the increase of burial depth and the horizontal stress is 1.5 - 5 times greater than that of the vertical when the depth is buried above $-1000 \mathrm{~m}$, but over than $-1000 \mathrm{~m}$, the horizontal stress is only 0.5 - 2 times of the vertical stress [7]. At present, the hypothesis generally considered in crustal stress that ground stress is equal in two horizontal directions doesn't reflect the real situation objectively. Consequently, the mechanical characteristics of deep rock mass in three directions under different ground stress are more complex.

Rock burst is a failure phenomenon of surrounding rock which caused by dynamic instability in the process of underground excavation engineering. Since the occurrence of rock burst has a certain impact on the regular production of underground rock excavation engineering and endanger the life safety of workers seriously, hence it has been paid attention by the scholars of mining and rock mechanics in various countries. From the strength theory, stiffness theory, energy theory, catastrophe theory, instability theory, fractal theory, rock burst tendency theory, fracture and damage theory [8]-[13] and other theoretical perspectives, they have carried out a lot of research and made some breakthroughs [14]-[19] on the deep physical and mechanical properties of rock mass, the constitutive relation of rock, rock burst induced mechanism, rock burst prediction, strata movement control method and support method. For the study of deep hard rock mechanics is still particularly emphasis on the deep rock stress field, physical and mechanical properties of deep rock mass and its constitutive relation, method of rock control and supporting under high stress, has also achieved some breakthroughs in research by now. Howbeit these researches are mostly concentrated in the laboratory or in the theoretical exploration stage, and study the problem basically from the static or quasi-static and pure dynamics point of view, thus there is still a gap in the actual requirements of the project. The mechanical behavior of deep rock under dynamic loading is essentially the mechanical mechanism of rock under static and dynamic combined loads. In this respect, it's more realistic to study the deep mechanical behavior of rock under dynamic loads. However, in the study of high stress rock mechanics, scholars only pay attention to the nature of rock under high static stress without considering the dynamic load of high stress rock. And for the study of dynamic characteristics, people usually lay stress on the nature of rock under the action of only dynamic load, overlook the dynamic characteristics of rock under high stress.

The formation of rock burst can be distinguished two major types. The first one is spontaneous rock burst of internal cause. When the stress around the excavation face exceeds the strength of the rock mass and causes rock failure in the form of sudden outburst, the increase of the stress is often related to the mining process nearby in such a condition. In addition, the weakening of the mechanical properties of rock with time or the loss of confining pressure are the signifi- 
cant issues for its sudden failure, all of which are related to the ratio of strength to stress of rock. The sudden energy release process is often triggered when the elastic energy stored in the rock mass can't be gradually dissipated. Especially, when the external loading stiffness is smaller than the unloading stiffness of the fracture body, the sudden damage is almost inevitable. And the second belongs to the external triggered. In some hard rock mines, large earthquake damage in the far field often induces sudden destruction of rock around the excavation structure, while the elastic energy released from the intact part is transmitted via stress wave to the surrounding rock mass of the excavation space, resulting in the sudden destruction of the excavation space. The introduction of the stress wave would fracture the rock around the underground space or give rise to the geometric instability of the underground structure and then induce rock burst, even directly provide enough strain energy to make the fractured rock mass ejected into the goaf. Rock dynamics research has also accumulated a lot of research results, which mainly related to rock burst and explosion or rock burst and explosion stress wave. The existing rock dynamics theory laid the foundation to solve these problems, but it can't or hasn't yet provide solutions for the every rock dynamics problems related to the rock burst mechanism.

The influence factors of rock burst are mainly related to mining depth, coal seam, properties and characteristics of roof and floor rock, geological structural factors and other mining geological factors as well as the mining technical conditions which include coal mining method, coal pillar, excavation sequence, blasting, roof management method. They are connected and restrict each other. It happens frequently in the rock burst mine where multiple factors exert simultaneous action and many factors will affect the occurrence of rock burst, such as in-situ stress, lithology, rock mass structure, burial depth, topography, artificial excavation. From here we can see that analyzing the influence of various factors on rock burst is of great significance for the study about rock burst mechanism and its reasonable prediction and prevention.

At present, rock burst prediction methods can be inducted as theoretical and actual measuring. Theoretical method which applies the established criteria or indicators of rock in order to predict rock burst via sampling and analysis of rock mass in underground engineering. And apropos of the actual measurement method, it directly monitors or tests the rock mass in underground engineering with some necessary instruments to determine whether there is a rock burst. Rock burst prediction method based on rock mechanics theory mainly include the maximum principal stress criterion, the maximum shear stress criterion, energy criterion, elastic strain energy index, explosive energy impact index and others; while the common used methods of actual prediction are the following: microseismic method, microgravity method, electromagnetic radiation monitoring and prediction method of coal-rock mass, seismological forecasting method, drilling cuttings method, moisture content method, photo-elastic method, rheological method. Moreover, in the theoretical prediction of rock burst, many 
of which are based on mathematical theory, these methods can be summed up fuzzy comprehensive evaluation method, BP neural network prediction method, fractal prediction method, prediction based on catastrophe theory and numerical analysis method.

It has been an main work for underground engineering design in the stage of design that apply the numerical analysis method to calculate the stress state of surrounding rock of chamber, according to the in-situ stress of rock mass and rock mechanics parameters. Nowadays, the calculation of the stress of elastic, elastic-plastic and viscoelastic surrounding rock is gradually becoming the routine work of underground engineering design, however, the numerical analysis method is seldom used to predict rock burst.

The rock has radial un-uniformity and contains various scales, which result in their influence on the failure of rock is more marked than macroscopic stress-strain relationship, therefore, such the strength of the rock mechanical parameters and deformation parameters of the deviation complex damage mechanism also would makes it difficult to calculate brittle failure. However, we can observe directly the brittle failure of the surrounding rock and cognize several regular information, and it may be helpful to establish the mathematical model and verify the reliability of the calculation according to the observed phenomena. This is a rough quantitative work done by precise calculations, with which the repeated process of observation-calculation-observation to achieve the prediction of the rock burst via progressively calculation. According to Russenses rock burst classification in Norway, where it is to describe apart the occurrence and development of rock burst by means of brittle rock beginning to fracture and eventually reaching the macroscopic destruction which obeys the Griffith criterion and Coulomb-NavVier or modified Griffith criterion respectively. What the stress strain relationship of rock can be approximately considered linear when it breaks from fracture to macro failure in order to convenient for numerical analysis, provides the possibility to predict whether rock burst occurs and estimate its intensity. Generally, numerical method is used to estimate the location, intensity and damage range of rock burst, and it has higher application value in production practice.

In the excavation of deep rock engineering, roadway or chamber excavated after rock burst and large deformation of surrounding rock occurred outside. In addition to rock burst disaster and large deformation of surrounding rock, there is a phenomenon of rock failure which would not be completely explained by traditional elastic-plastic mechanics in some specific conditions or places, that is to say, the rock mass behind excavated surface is in the process of excavation where the failure zone and non destruction present alternately; hence the name, zonal disintegration phenomenon [20]. On the zonal disintegration phenomenon of mining analysis, mechanical excavation of mine will also appear in zonal disintegration, and the results denied it is caused by blasting. Once there certain conditions are satisfied, it is considered that the phenomenon can occur whether 
drilling and blasting construction or mechanical method. Academician Qi-hu Qian put forward that the phenomenon of deep zonal disintegration is a scientific phenomenon of comprehensive spatial time effect coupling [21], which should be across-the-board considered that the one is rock splitting failure caused by high stress and unloading, the other, however, is energy flow effect induced by high stress and stress gradient where excavation stress unloading acting on the excavation face.

Rock burst and zonal disintegration in which deep rock mass excavated shows that there is fracturing on surrounding rock, in the process of stress release in high stress energy storage rock mass. With characteristics which "easy drill easy explode" and tendency of spontaneous cracking after small disturbance where deep hard rock is excavating, starting from the its stress characteristics, what has been an urgent research topic to meet deep mining is that how to effectively prevent and avoid rock burst, zonal disintegration and other disasters accidents, achieve the target that releasing and controllable utilizing original stored energy of in high-stressed hard rock. Currently, in the terms of stress unloading or dynamics, the domestic and foreign studies are aimed at the above mentioned characteristics of deep rock stress damage in order to research the unloading damage and dynamic characteristics by means of experimental equipment with triaxial equipment and the devices based on split Higginson pressure bar (SHPB) or light gas gun respectively, from the point of high stress release or dynamic destruction.

\subsection{Research Status and Trend Analysis about Fracture and Failure Effects on Deep Rock Mass under Impulse Loading}

In the early $80 \mathrm{~s}$ of the last century, He-Ping Xie [22] has established a macroscopic damage mechanics model for fractured rock mass, expanded the damage mechanics field of fractured rock mass, and introduced fractal method to study discontinuous deformation, strength and fracture or failure on fractured rock mass. With the intensive study on rock mechanics, scholars have begun to study the influence of strain rate on modulus of elasticity, strength, damage and the other parameters of rock materials under blasting loading and earthquake loading. Widely applied acoustic emission technology into the study of rock damage and failure mechanism, Tan Chunan [23] presented the idea that AE of rock is associated with rock damage. From micro aspect, Xu jiang [24] analyzed the fracture damage of sandstone at different loading stages by optical microscope. Huang Shuhua [25] made an introduction about the advantages of CT device apply into the study of rock damage and fracture, while Kawakata [26] built 3D CT image combined with the CT scanning data of rock samples, where the distribution and patterns of cracks would be observed intuitively.

Investigated from the energetic point of view, the deformation and failure of rock is the process of transmitting incident energy into rock and transforming into internal energy and kinetic energy. Gao Wenxue [27] studied the relation- 
ship between dynamic damage of rock and its evolution law and ultrasonic attenuation, established a model which can describe how the rock is impact compressed and tensile damaged on the basis of principle of damage energy dissipation. Using formula derivation and theoretical study which based on the brittle dynamic fractural criterion, Li Xibing [28] analyzed energy dissipation of rocks under impulsive loading with different waveforms, such as rectangular, symmetric bell-shaped and exponential-attenuation pulses. Xie Heping [29] researched the process of rock deformation and failure from the aspect of energy, through theoretical and experimental research, concluded that stress-strain strength would not well describe the characteristics of rock failure while energy plays a fundamental role in rock deformation and failure, and the other, catastrophic process of rock is a typical energy release process.

On the model of rock failure under impact load, Chen Qingshou [30] divided nine kinds of rock into three categories, and tested them with dynamic load. According to the results of failure modes, they are divided into: cracks, moderate damage and strong crushing. Zhai Yue [31] made a study about the crushing degree and crushing forms of granite and concrete specimens under impact loading, where he found that the fragmentation degree will get serious with strain rate increases and as the strain rate increases, the number of fragments increased while size decreased, the main failure mode of granite at high-low strain rates is axial splitting tensile condition. Ping Qi [32] has tested the dynamic compressive mechanical properties of sandstone in coal mine via SHPB equipments and raised the conclusion that rock specimen periphery would spall when strain rates is low, higher the rock would be power after failure, with the strain rates increasing, fragments size decreased as well as an increase in number. Ren-liang Shan [33] did a great quantity of impact tests on marble and granite, summed up there are four main impact failure modes: shear, tensile stress, extensible strain and unloading damage, considered that the reasons of the above failure are related to the physical properties, internal structure, microcrack distribution of rock itself.

Comprehensive research shows that the impact load has a major influence on the deformation and failure of deep rock mass, which is the mechanical origin of zonal disintegration, tensile and compressive damage, elastic loss and plastic failure. Since deep underground engineering is an excavation activity carried out in the underground 3D space, hence, deep rock mass must be affected by superposition of high-stress field, high-permeability pressure, high surrounding rock pressure field, coupled with strong disturbance of impact load, where it makes dynamic appearance characteristics and damage and fracture rules of deep rock mass more complicated. Therefore, it is of great significance to the maintenance safety and stability of deep rock mass that researching the catastrophic inducement and developing mechanism of deep high-stress rock mass under impact loading and constructing model of instability-fracture evolution on the condition of impact disturbance. 


\section{Later Research Contents}

\subsection{Static and Dynamic Characteristic of Deep High Stress Rock Mass under Impulse Loads}

To test the deformation and failure characteristics and stress-strain law of typical deep rock, which under different impact loading, by means of rock mechanics test, the RMT-150 triaxial strength equipment, and investigate its static triaxial deformation properties and failure strength characteristics, and failure process of energy storage and release. On the basis of Hopkinson (SHPB) experimental system, researching dynamic mechanical properties of deep hard rock in different three-dimensional pre-stressed conditions with changing the specimen confining, axial pre-stressed and the dynamic loading forms, discussing the deformation and failure characteristics of pre-stressed deep rock under medium-high strain rate, exploring its fracture and failure mechanism, and build dynamic constitutive model and bring forward its failure criterion.

\subsection{Disturbance Response Characteristics of Deep High Stress Rock Mass under Impulse Loads}

The dynamic disturbance response law and dynamic failure characteristics of deep high stress rock mass under the impact load such as high speed impact, transient explosion and high efficiency outburst are studied. The energy accumulation, transformation and release law of high energy storage rock mass are explored by analyzing the energy change of rock mass under impact loading during the process of rock failure under pre stress loading.

\subsection{Catastrophe Developing Mechanism of Deep High Stress Rock Mass under Impulse Loads}

The research on deep high stress rock mass accumulation in a large number of internal strain energy under the condition of impact triggered deep rock dynamic catastrophe instability characteristics and regularity, and find out the stress energy catastrophe in strong shock under the disturbance of rock mass stress evolution mechanism of inoculation, and the impact of the dynamic response of deep and high stress. Rock mass deformation and instability, fracture time until the disaster induced evolution model of deep high stress impact load construction, establish mechanics criterion and evaluation system of disaster triggered.

\section{Research Methods and Ideas}

The dynamic-static rock mechanics experiment and comprehensive methods of theoretical analysis and numerical simulation approach to catty out the research. By using of the dynamic-static rock mechanics experiment to explore the special mechanical properties of rock mass in great depth. And with the assistance of the experiments to ascertain response characteristics and instability rules in 
high-stress rock mass under shock disturbed, analysis its catastrophe developing mechanism of, investigate its deformation and failure law and the dependence with catastrophe under shock disturbed, establish the space-time evolution model and catastrophe evaluation system about high-stress rock mass involved the deformation and instability, fracture and failure until catastrophe inducement. Specific solutions are as follows.

\subsection{Static Mechanic Experiments on High-Stress Rock Mass}

Typical deep hard rock (such as granite, marble, sandstone etc.) are selected for the triaxial mechanical experiments under different test conditions; the different confining pressure, different confining pressure unloading speed, and triaxial multicyclic loading-unloading mechanics experiment with diverse unloading levels. On the basis of obtaining abundant experimental data, the static failure mode of deep high-stress hard rock is gained, and the static constitutive characteristics and failure criterion of hard rock are established.

\subsection{Dynamic Mechanic Experiments on High-Stress Rock Mass}

According to the stress state of deep rock, the triaxial test system based on SHPB was adapted to carry out 3D dynamic rock mechanics experiment under no impact and impact loading conditions. Considering different surrounding rock, different axial load prestress loading for the 3D impact stress rock mass, the deformation mechanical properties and failure mechanism of high-stress rock mass are achieved by controlling the strain rates. Moreover, we also can build dynamic constitutive model about deep rock with the state of impact loads, explore its high-stress response characteristics and failure law under dynamic shock disturbance.

\subsection{Theoretical Analysis on High-Stress Rock Mass under Impulse Loading}

Making a contrastive study of results of which static and dynamic triaxial rock mechanics experiment, analysis the similarities and differences about the rock mechanic parameter, failure modes, constitutive relations under different loading methods, confining conditions, loading levels as well as others, and discuss the macro and micro mechanism of disturbance instability and catastrophic occurrence of deep rock mass under different impact loading conditions.

\subsection{Numerical Simulation of Catastrophic Evolution Mechanism of Deep High-Stress Rock Mass under Impact Loading}

Based on dynamic and static rock mechanics experiments and theoretical analysis, using numerical simulation software such as FLUENT, FLAC3D, we can introduce the dynamic-static constitutive model and failure criterion in order to construct mechanical model and evaluation method about disaster triggered, in addition to build a simulation on the impact load conditions, what about the 
whole process of evolution mechanism how the deep high-stress rock mass from deformation and instabilities to fracture and failure until the disaster induced.

\section{Conclusions and Prospection}

1) Due to concentrated effect of superimposed high-stress such as high in-situ stress field, high permeable pressure field and high surrounding rock pressure field coupled with the strong disturbance of impact load, it result in the dynamic characteristics of the deep rock mass and the law of damage and fracture being more complex. Therefore, it plays a vital role to ensure the security and stability of deep rock mass studying on the catastrophic induced formation mechanism and evolution mechanism of deep high stress rock mass under impact loading and constructing its instability fracture evolution model under impact disturbance.

2) Through investigating and mastering dynamic-static mechanical properties of deep high-stress rock mass under shock disturbance, we would explore rock damage and fracture mechanism with different conditions of impact loads, establish dynamic constitutive model and failure criterion of deep rock under different impact load, construct the catastrophic evolution model of deep high-stress rock mass under impact disturbance and reveal the catastrophic induction mechanism, stress evolution law and impact dynamic response about deep high-stress energy-storaged rock mass under impact loading.

\section{Acknowledgements}

This work is supported by Research project of Hunan Education Department (Grant No. 17C1537), Key Laboratory of Safety and High-efficiency Coal Mining, Ministry of Education (Grant No. JYBSYS2018203), Hunan Key Laboratory of Geomechanics and Engineering Safety (Grant No. 16GES10) and Xiangtan University Natural Science Foundation (Grant No. 15XZX41).

\section{Conflicts of Interest}

The authors declare no conflicts of interest regarding the publication of this paper.

\section{References}

[1] Xie, H.P., Gao, F. and Ju, Y. (2015) Research and Development of Rock Mechanics in Deep Ground Engineering. Chinese Journal of Rock Mechanics and Engineering, 34, 2161-2178.

[2] Cui, C.G. (2016) Study on Nonlinear Deformation and Damage of Rock under Impulse Loading. Yanshan University, Qinhuangdao.

[3] Wang, X.F., Gao, M.Z. and Li, L.Q. (2016) Spatiotemporal Coupling Law of Mining Pressure, Strata Movement and Fracture Field Distribution in Deep Stope. Journal of Mining and Safety Engineering, 33, 604-610.

[4] He, M.C. (2005) Conception System and Evaluation Indexes for Deep Engineering. 
Chinese Journal of Rock Mechanics and Engineering, 24, 2854-2858.

[5] He, M.C. and Qian, Q.H. (2006) Summarize of Basic Research on Rock Mechanics at Great Depth. Science Press, Beijing.

[6] He, M.C., Xie, H.P. and Peng, S.P. (2007) Summarize of Basic Research on Rock Mechanics and Engineering Disaster Control at Great Deep Exploitation. Coal Mine Supporting, 3, 1-14.

[7] Brown, E.T. and Hoek, E. (1978) Trends in Relationships between Measured Rock In-Situ Stress and Depth. International Journal of Rock Mechanics and Mining Sciences \& Geomechanics Abstracts, 15, 211-215. https://doi.org/10.1016/0148-9062(78)91227-5

[8] Xu, Z.H. and Xu, X.H. (1997) Cusp Catastrophe of Occurrence Condition and Time Effect of Rock Burst in Pillar Mining. Transactions of Nonferrous Metals Society of China, 7, 17-23.

[9] Shan, X.Y., Xu, D.Q. and Zhang, Y .B. (2000) Prediction of Possibility of Rock Burst in Roadway by Catastrophe Theory. Mine Surveying, 4, 36-37.

[10] Li, G.P. (1997) Damage Fracture Model of Rock Burst. Geotechnical Mechanics, 18, 105-109.

[11] Wang, Y.H., Li, W.D. and Li, Q.G. (1998) Fuzzy Mathematics Comprehensive Evaluation Method for Rock Burst Prediction. Journal of Rock Mechanics and Engineering, 17, 493-501.

[12] He, M.C., Miao, J.L. and Li, D.J. (2007) Experimental Study on Rock Burst Processes of Granite Specimen at Great Depth. Journal of Rock Mechanics and Engineering, 26, 865-876.

[13] Guo, R. and Yu, R.C. (2002) Support Design of Roadway with Rock Burst Danger. China Mining Magazine, 11, 23-28.

[14] Li, S.L. (2000) Study on Rock Burst Proneness and Strata Control Technology of Hard Rock in Deep Well. Northeastern University, Jilin.

[15] Xu, Z.M., Huang, R.Q. and Fan, Z.G. (2004) Research Progress of Rock Burst Disaster in Large Tunnel. Journal of Natural Disasters, 13, 16-24.

[16] Gong, F.Q. and Li, X.B. (2007) A Distance Discriminant Analysis Method for Prediction of Possibility and Classification of Rock Burst and Its Application. Chinese Journal of Rock Mechanics and Engineering, 26, 1012-1018.

[17] Li, X.B., Zuo, Y.J. and Ma, C.D. (2005) Failure Criterion of Strain Energy Density and Catastrophe Theory Analysis of Rock Subjected to Static-Dynamic Coupling Loading. Chinese Journal of Rock Mechanics and Engineering, 24, 2814-2824.

[18] Zhang, Z.Y., Wang, S.T. and Wang, L.S. (1980) Principles of Engineering Geology Analysis. Geology Press, Beijing.

[19] Tan, Y. (1989) Study on Formation Mechanism of Rock Burst. Hydrogeology and Engineering Geology, 1, 34-38.

[20] Qian, Q.H. and Li, S.C. (2008) A Review of Research on Zonal Disintegration Phenomenon in Deep Rock Mass Engineering. Chinese Journal of Rock Mechanics and Engineering, 27, 1278-1284.

[21] Qian, Q.H. (2004) The Key Scientific Issues in the Development of Deep Underground Space. Engineering Corps College of PLA University of Science and Technology, Nanjin.

[22] Xie, H.P., Peng, R.D. and Ju, Y. (2004) Research Progress Rock Strength Theory Based on Fracture Mechanics and Damage Mechanics. Progress in Natural Science, 
14, 1086-1092.

[23] Tang, C.N. (1997) Preliminary Study on Numerical Simulation of Rock Acoustic Emission Law. Chinese Journal of Rock Mechanics and Engineering, 4, 268-272.

[24] Xu, J., Li, H. and Xian, X.F. (1986) Experimental Study on Micro Fracture Development of Sandstone under Uniaxial Stress. Mechanics in Enginering, 4, 16-20.

[25] Huang, S.H. (1989) Application of AE and CT Devices in Rock Mechanics-Recent Developments of Rock Mechanics in Kyoto University, Japan. Rock and Soil Mechanics, 1, 83-86.

[26] Kawakata, H., Cho, A., Yanagidani, T., et al. (1997) The Observations of Faulting in Westerly Granite under Triaxial Compression by X-Ray CT Scan. International Journal of Rock Mechanics \& Mining Sciences, 34, 151.e1-151.e12. https://doi.org/10.1016/S1365-1609(97)00138-X

[27] Gao, W.X., Liu, Y.T. and Yang, J. (2000) Study on Impact Damage of Brittle Rock. Chinese Journal of Rock Mechanics and Engineering, 19, 153-156.

[28] Li, X.B. and Gu, D.S. (1994) Theoretical Study on Energy Dissipation of Rock under Different Loading Conditions. Chinese Journal of Rehabilitation Medicine, 14, 129-139.

[29] Xie, H., Peng, R. and Ju, Y. (2005) On Energy Analysis of Rock Failure. Chinese Journal of Rock Mechanics and Engineering, 24, 2603-2608.

[30] Chen, Q.S. and Wu, H.R. (1987) Failure and Strength of Rock under Dynamic Loading. Journal of Wuhan College of Geology, 12, 206-216.

[31] Zhai, Y., Ma, G.W. and Zhao, J.H. (2007) Dynamic Failure Analysis on Granite under Uniaxial Impact Compressive Load. Chinese Journal of Geotechnical Engineering, 172, 385-390.

[32] Ping, Q., Ma, Q.Y. and Yuan, P. (2013) Dynamic Compression Properties Tests of Sandstones from Coalmine by SHPB Apparatus. Journal of Anhui University of Science and Technology, 33, 40-44.

[33] Shan, R.L. and Zhu, Z.Q. (1998) Study on Failure Modes of Marble Granite under Impact Loading. Chinese Journal of Rock Mechanics and Engineering, 17, 774-779. 